\title{
Initial Rheological Description of High Performance Concretes
}

\author{
Alessandra Lorenzetti de Castro*, Jefferson Benedicto Libardi Liborio* \\ Laboratory of Cement-based Advanced Materials, Department of Structural Engineering, \\ São Carlos Engineering School, University of São Paulo \\ Av. Trabalhador Sancarlense, 400, Centro, 13566-590 São Carlos - SP, Brazil
}

Received: May 24, 2006; Revised: September 10, 2006

\begin{abstract}
Concrete is defined as a composite material and, in rheological terms, it can be understood as a concentrated suspension of solid particles (aggregates) in a viscous liquid (cement paste). On a macroscopic scale, concrete flows as a liquid. It is known that the rheological behavior of the concrete is close to that of a Bingham fluid and two rheological parameters regarding its description are needed: yield stress and plastic viscosity. The aim of this paper is to present the initial rheological description of high performance concretes using the modified slump test. According to the results, an increase of yield stress was observed over time, while a slight variation in plastic viscosity was noticed. The incorporation of silica fume showed changes in the rheological properties of fresh concrete. The behavior of these materials also varied with the mixing procedure employed in their production. The addition of superplasticizer meant that there was a large reduction in the mixture's yield stress, while plastic viscosity remained practically constant.
\end{abstract}

Keywords: rheology, yield stress, plastic viscosity, high performance concrete

\section{Introduction}

In general, concretes and mortars are composite materials, and cement, aggregates and water are the main components. Thus, concrete can be understood as a concentrated suspension of solid particles (aggregates) in a viscous liquid (cement paste). In turn, cement paste does not represent a homogeneous fluid, which is composed of particles (cement grains) and a liquid (water). On a macroscopic scale, concrete flows as a liquid ${ }^{1}$.

Traditionally, the behavior of fresh concrete can be summed up in one word: workability, which does not correspond to an intrinsic property of the material. It is related to the easiness that a certain concrete type can occupy a mold, within the expectations for which it was designed.

In concrete technology, this term has often been used to include all the necessary qualities to one mixture, which can include (under the same name) the requirement stability. In other words, the mixture is capable of resisting segregation and bleeding ${ }^{2}$. Obviously, the workability level required for a concrete depends on the situation in which the material is used.

Therefore, as the fresh concrete is a fluid, in order to study its behavior under strain, there is nothing more appropriate than finding the rheology concepts (the science which concerns the study of deformation and flow of a fluid under stress influence).

The rheological properties of fresh concrete are mainly important at the time when the material is placed in formworks and they can be determined at any moment in a dormant period of cement hydration ${ }^{3}$.

Using rheology to study concrete workability is not very common. Generally, slump is the only parameter which is measured and, even in a laboratory, studies rarely supply additional information concerning the flow behavior of these materials.

It is known that the consistency given in terms of slump value is related to yield stress, however no information regarding the behavior under higher shear rate is obtained. Moreover, a slump test is an empirical measure, as is establishing a correlation with it.
Only by determining the fundamental rheological parameters, such as yield stress and plastic viscosity, one can take advantage of the vast knowledge concerning suspension rheology ${ }^{4}$. Thus, a complete description of the concrete flow behavior has more advantages than the slump test.

Unfortunately, due to the complex concrete composition, there is no defined method to predict the flow of material from its components. Even the measures of the rheological parameters cannot be easily taken due to the wide size range of particles found in the mixture. Therefore, the flow of a certain concrete is usually measured using one of the various available standards tests, where the intrinsic flow properties of the material are measured partially ${ }^{5}$.

\subsection{Rheology of fresh concrete}

Despite various research projects that are being developed to define fresh concrete flow properties, the existing test methods still do not determine rheological properties which are similar to the same concrete $^{6}$. The variations are mainly due to the differences in terms of the experimental techniques and equipment used. Furthermore, most current test methods are usually complicated, requiring ability and they are not easily carried out on site.

All the standard tests, as well as any other empirical test, try to assess workability in terms of a single quantity, be it a slump value, a Vebe time, or any other, so that all of them take into account the implicit consideration that the concrete behaves in the simplest way possible, such as water. However, the most casual observation of the concrete behavior shows that this assumption cannot be true.

It can be observed that the material requires the imposition of a minimum stress or force to start its flow, which indicates that there is a yield stress and, consequently, its flow curve will not pass through the origin. Taking this into consideration, the concrete cannot be described by a unique constant. To discover what the form of the flow curve of this material is, some experiments should be developed in which the measures are taken for a series of different flow speeds ${ }^{5}$. 
Most of the equations used for concentrated suspensions, such as concrete, try to relate the suspension concentration to the viscosity or the shear stress to the shear rate, thus assuming that there is only one value for the viscosity of the whole system ${ }^{1}$. A series of studies developed in the attempt of describing the fresh concrete behavior is presented in Table 1 .

The rheology of fresh concrete is very complex due to its composition and to accompanying chemical changes. Various researchers have already described fresh concrete as a complex non-Newtonian fluid that has a yield stress and a viscosity which is dependent on the shear rate, seeing that both change with time: as the concrete hardens the yield stress and the viscosity increase ${ }^{7}$.

In the literature, due to extensive experimental evidence of the flow properties of fresh concrete, it was concluded that the material behaves as a Bingham fluid ${ }^{1,5}$, that is, the material does not flow until a particular stress is exceeded. Thus, the stress which is necessary for a material flow - shear stress $(\tau)$ - is equal to the sum of yield stress $\left(\tau_{o}\right)$ and of another term proportional to the shear rate $(\dot{\gamma})$ (Equation $1)$. The proportionality factor in the second term is called plastic viscosity $(\mu)$ and its inverse, fluidity.

$$
\tau=\tau_{o}+\mu \dot{\gamma}
$$

According to Tanner ${ }^{8}$, the explanation for the behavior of a Bingham fluid is that the fluid, in rest, contains a three-dimensional structure of sufficient rigidity to resist any stress less than the yield stress. If this stress is exceeded, the structure disintegrates and the system behaves as a Newtonian fluid under a certain shear stress; when the shear stress that acts in a system is reduced and it reaches values lower than the yield stress, the three-dimensional structure is recuperated.

As the main factor responsible for forming the three-dimensional structure is the attraction among the particles of a suspension, all the variables that support the performance of such attractive forces also contribute to the appearance of yield stress in a suspension ${ }^{9}$.

Therefore, there is no doubt that the flow properties of the fresh concrete approach of a Bingham fluid. In this case, the material should be evaluated in terms of two constants: yield stress and plastic viscosity. The first rheological parameter is related to the slump, while the latter makes the difference between a "worker-friendly" concrete from that having a "sticky" behavior, being hard to pump and displaying coarse bubbling at the form removal ${ }^{10}$.

According to Tattersall and Banfill ${ }^{2}$, it should not forget that the Bingham model is in fact a model and there is no cause for surprise

Table 1. Rheological models applied to the fresh concrete ${ }^{1}$.

\begin{tabular}{ll}
\hline \multicolumn{1}{c}{ Model name } & \multicolumn{1}{c}{ Equation } \\
\hline Newton & $\tau=\mu \dot{\gamma}$ \\
Bingham & $\tau=\tau_{o}+\mu \dot{\gamma}$ \\
Herschel-Bulkley & $\tau=\tau_{o}+K \dot{\gamma}^{n}$ \\
Power equation & $\tau=A \dot{\gamma}^{n}$ \\
& $n=1$, for Newtonian fluid \\
& $n>1$, for shear thickening \\
& $n<1$, for shear thinning \\
Vom Berg, & $\tau=\tau+B \operatorname{sen}^{-1}(\dot{\gamma} / C)$ \\
Ostwald-de-Waele & $\tau=a \dot{\gamma}+B \operatorname{sen}^{-1}(\dot{\gamma} / C)$ \\
Eyring & $\tau=a(\dot{\gamma}+C)^{b}$ \\
Robertson-Stiff & $\dot{\gamma}=\alpha \tau^{2}+\beta \tau+\delta$ \\
Atzeni et al. &
\end{tabular}

Variable definitions:

$\tau=$ shear stress; $\tau_{o}=$ yield stress $; \mu=$ viscosity $; \dot{\gamma}=$ shear rate

$A, a, B, b, C, K, \alpha, \beta, \delta=$ constants. if the behavior of real materials fits it less than perfectly. In fact, the equation satisfactorily describes the flow properties of many concentrated suspensions over a more or less limited range of shear rates, but in agreement with the authors' experience ${ }^{2}$, the behavior of real materials departs significantly from the model in at least one of the following aspects: the up and down curves are not coincident; the yield stress is not well defined; and the flow curve is not linear, except over a very limited range of shear rates.

\subsection{Measurement of fresh concrete rheological properties}

The size of the biggest aggregate in a concrete makes the use of traditional rheometers impossible, such as a capillary viscosimeter or a cylindrical viscosimeter. Due to the difficulty in identifying the true rheological behavior of concretes, some comparative tests are used. Some of them can be standardized and they are easily implemented and cheap. They show approximately the static or dynamic behavior of the cement paste using global values (setting, spreading, flowing duration), which are not often linked to the specific values of the tested material ${ }^{11}$.

Any test that describes the flow behavior of fresh concrete should measure, at least, the two rheological parameters. The requirement for the two constants is not just a question of scientific precision, but also a matter of great practical importance for the control itself and use of the concrete. Unfortunately, most existing tests only measure one of these parameters, related to the yield stress or plastic viscosity.

In fact, the single-point methods can only reflect the result of fresh concrete to a particular shear rate. To obtain a more appropriate description of the flow behavior of this material, the properties should be tested within a certain range of the shear rate while the concrete flows ${ }^{12}$.

For high performance concrete (HPC), workability is evaluated using the same tests as were used for normal concrete, however its specific characteristics hinder the correct interpretation of these tests $^{1}$. In the slump test, for example, it can be demonstrated that the yield stress is within the desired range, but the viscosity, which is not measured by this test, may be as high as the mixture (termed as "sticky") becomes difficult to be placed even under vibration.

As well as evaluating the flow behavior of the concrete, one must be concerned about predicting the flow of its components properties (cement paste and/or mortar) or its mix design (water/cement and/or water/binder ratios, aggregate content, cement type and admixtures dosages $)^{1}$. However, no attempt in developing a model like this was successful. The first difficulty stems from the fact that the size range of the particles found in the concrete is very wide (from $1 \mu \mathrm{m}$ for cement grains to $25 \mathrm{~mm}$ for some aggregates). Secondly, the quantity of factors that influence the flow properties of concrete is larger than the quantity of that influence the rheology of its parts (cement paste and aggregates).There is no linear relationship among the rheological parameters of cement paste and those of concrete, whose main reason is the gap between aggregates, which varies according to concrete cement paste volume content.

Thus, there is no doubt that flow properties of fresh concrete are close to a Bingham fluid and, therefore, the material should be evaluated by two constants: yield stress and plastic viscosity.

Among the tests that are capable of measuring the two rheological constants of a concrete, the two-point workability test, the Bertta apparatus and the rheometer are worth mentioning. Recently, a modification in the slump test has been used as a test method which is able to determine the rheological parameters.

As the traditional slump test is able to measure only properties related with the yield stress of the concrete, a modification was made to obtain measures related to the plastic viscosity. Therefore, in terms of the description of viscosity, Ferraris and de Larrard ${ }^{13}$, authors of the modification, decided to base on a mean slump value during the test. 
Consequently, necessary intervals of time to reach the intermediate height between initial and final slump values seemed, a priori, a good way to describe the viscosity of the concrete.

According to the authors, since the slump range of concretes capable of being evaluated by the rheometer is greater than $100 \mathrm{~mm}$, this value was adopted as the value of a partial slump. Thus, in the test modification, a plate was used, which slid onto a centrally located rod as a means of monitoring the time to reach the slump of $100 \mathrm{~mm}$ (Figure 1).

In order to measure the partial slump time, a stopwatch controlled by an operator was used. This stopwatch was started as soon as the slump cone mold was lifted and it stopped when the sliding plate, placed on the surface of the fresh concrete, reached the $100 \mathrm{~mm}$ mark and was joined in this position (Figure 2).

Concerning the calculation of rheological parameters, yield stress and plastic viscosity, from of the data obtained in this test, equations where the yield stress and the plastic viscosity are related to the final slump and the partial slump time of the fresh concrete, respectively, were developed.

$$
\begin{array}{ll}
\tau_{o}=\frac{\rho}{347}(300-S)+212 & \\
\mu=1,08.10^{-3}(S-175) \rho T & \text { For: } 200 \mathrm{~mm}<S<260 \mathrm{~mm} \\
\mu=25.10^{-3} \rho T & \text { For: } S<200 \mathrm{~mm}
\end{array}
$$

where $\tau_{o}$ is the yield stress expressed in $[\mathrm{Pa}], \mu$ is the plastic viscosity in $[\mathrm{Pa} . \mathrm{s}], \rho$ is the density of concrete in $\left[\mathrm{kg} / \mathrm{m}^{3}\right], S$ is the final slump in $[\mathrm{mm}]$ and $T$ is the partial slump time in [s].

\section{Experimental Procedure}

Concerning the production of high performance concretes that were studied, the following materials were used: high early strength and sulfate resistant portland cement (CPV ARI RS - ABNT) of which the specific gravity is $3.08 \mathrm{~g} / \mathrm{cm}^{3}$ and chemical and potential (given by Bogue's equations) compositions are shown in Table 2;

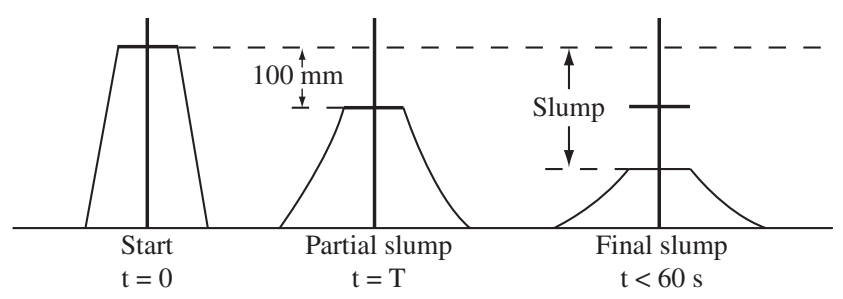

Figure 2. Scheme of the modified slump test ${ }^{13}$.

Table 2. Chemical and potential compositions of used cement.

Chemical composition

\begin{tabular}{cc} 
Chemical constituent & Cement mass $(\%)$ \\
\hline $\mathrm{SiO}_{2}$ & 22.32 \\
$\mathrm{Fe}_{2} \mathrm{O}_{3}$ & 1.72 \\
$\mathrm{Al}_{2} \mathrm{O}_{3}$ & 5.50 \\
$\mathrm{TiO}_{2}$ & 0.17 \\
$\mathrm{CaO}$ & 63.61 \\
$\mathrm{P}_{2} \mathrm{O}_{5}$ & 0.19 \\
$\mathrm{MgO}$ & 1.45 \\
$\mathrm{Na}_{2} \mathrm{O}$ & 0.25 \\
$\mathrm{~K}_{2} \mathrm{O}$ & 0.63 \\
Loss in ignition & 4.15 \\
\hline & Potential composition $(\%)$ \\
$\mathrm{C}_{3} \mathrm{~S}$ & 38.26 \\
$\mathrm{C}_{2} \mathrm{~S}$ & 7.66 \\
$\mathrm{C}_{3} \mathrm{~A}$ & 4.92 \\
$\mathrm{C}_{4} \mathrm{AF}$ & 6.32 \\
\hline
\end{tabular}

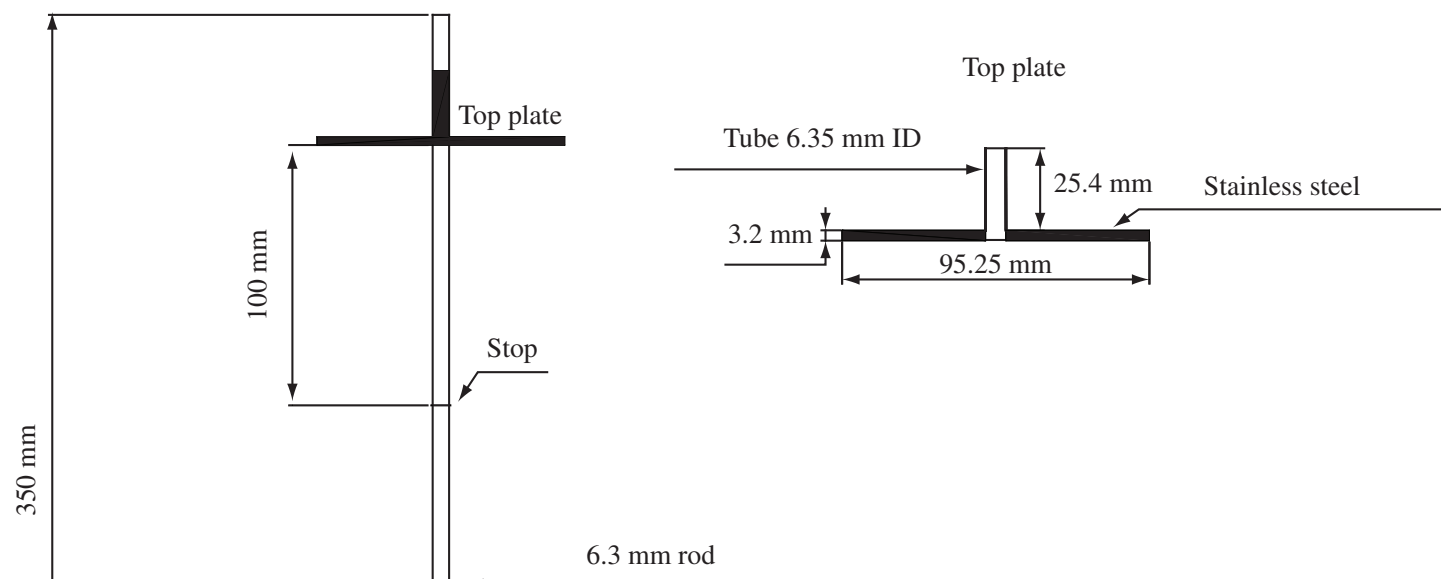

Figure 1. Rod in the modified slump apparatus. Top plate in detail ${ }^{13}$. 
sand quatzous with fineness modulus and maximum size of 2.34 and $4.8 \mathrm{~mm}$, respectively; two crushed aggregates of basaltic origin with maximum sizes of $19 \mathrm{~mm}$ and $25 \mathrm{~mm}$, classified, respectively, as crushed rocks 1 and 2 according to Brazilian standards; polycarboxylate based superplasticizer (SP), with a content of $0.20 \%$ (desired slump $=160 \mathrm{~mm} \pm 20 \mathrm{~mm}$ ); silica fume in the content of $10 \%$ in cement volume substitution; and mixing water corresponding to a water/binder ratio $(\mathrm{w} / \mathrm{b})$ of 0.40 .

For the mix design used $(1: \mathrm{m}=3.5)$, in which $\mathrm{m}$ is the total of aggregates, the consumption of mixture constituents is presented in Table 3. In order to observe the influence of aggregates, SP presence and silica fume incorporation, three concretes were made: the HPC/ $\mathrm{R} 0$, with no presence of any chemical or mineral additions; the HPC/ $\mathrm{R} 1$, only incorporated with SP; and the HPC, incorporated both with SP and silica fume, whose definitions are presented in Table 3.

In terms of the evaluation concerning the influence of the mixing procedure on fresh concrete rheological parameters, six different procedures (Figure 3) were used to produce high performance mixtures, and the order of placing the constituent materials was varied. They were based on the mixing procedure widely used in practice by Brazilian concrete plants (procedure A) and a SP variation addition was considered (procedures B and C). In procedures D and E, an attempt was made to saturate the aggregates before adding binder materials; the difference between them is when SP is added. In procedure F, the binder materials were first mixed and, only after, the aggregates, the mixing water and SP were added.

The total mixing time was kept constant for all the procedures which were followed. A period of nine minutes to complete the complete concrete production was considered.

The rheological description of the concrete mixtures was carried out by the modified slump test. It is called initial because, later, a rheometer will be used to check the values obtained as well as the flow behavior presented by the mixtures.

The concrete behavior was analyzed in a period of two hours, and measurements of the final slump and partial slump time at 10 , 30, 60, 90 and 120 minutes after cement-water contact were taken. Thus, the slump loss of these mixtures by means of the evolution of their rheological parameters over time can be observed.

The test conditions were kept constant: relative humidity higher than $65 \%$ and room temperature at $23{ }^{\circ} \mathrm{C} \pm 3{ }^{\circ} \mathrm{C}$.

\section{Results and Discussion}

Concerning the rheological description of the high performance concretes, the modified slump test developed by Ferraris and de Larrard $^{13}$ was used. In this test, by determining the final slump value and the partial slump time (Table 4), it was possible to specify the yield stress and plastic viscosity of the material by means of the equations 2 and 3, respectively, whose values are presented in Table 5. The yield stress curves vs. time for the studied mixtures are presented in Figure 4.
The lower the yield stress of a concrete, the easier the beginning of the flow, and the higher its fluidity, consequently, the lower its viscosity. In all the mixtures, an increase in the yield stress could be observed over time, indicating workability loss, because as time passed the mixture fluidity reduced and the resistance to be exceeded to start the flow increased.

The SP effect on the concrete rheological properties could be observed when comparing the mixtures HPC/R0 and HPC/R1. It could be seen that by incorporating $0.20 \%$ of SP to the mixture resulted in a reduction of $42 \%$ in the yield stress, while the plastic viscosity remained practically constant.

A reduction in yield stress could be observed at the beginning of the test, because over time a large increase in this parameter was

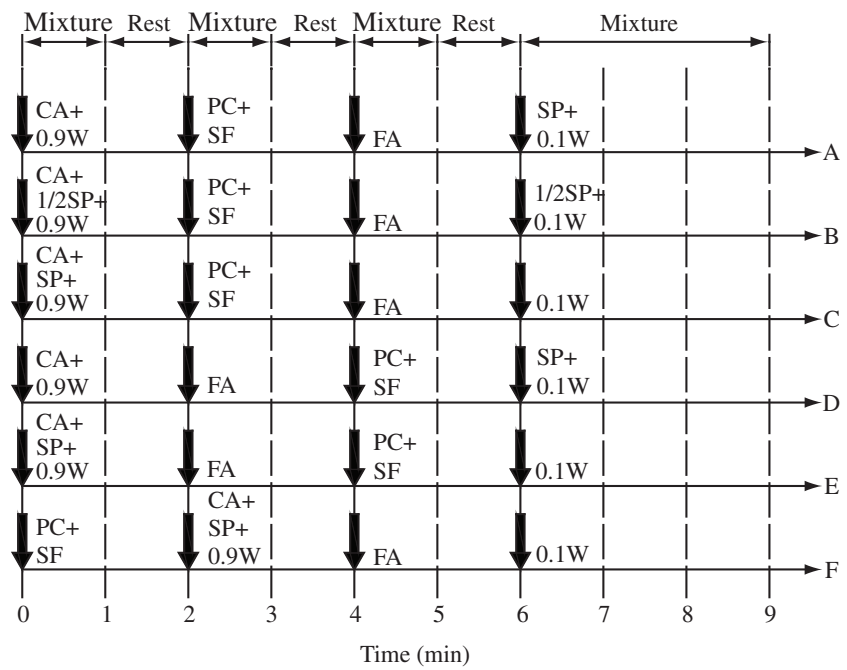

Figure 3. Mixing procedure used in high performance concretes production, where: $\mathrm{W}=$ water, $\mathrm{FA}=$ fine aggregate, $\mathrm{CA}=$ coarse aggregate, $\mathrm{PC}=$ portland cement, $\mathrm{SF}=$ silica fume and $\mathrm{SP}=$ superplasticizer.

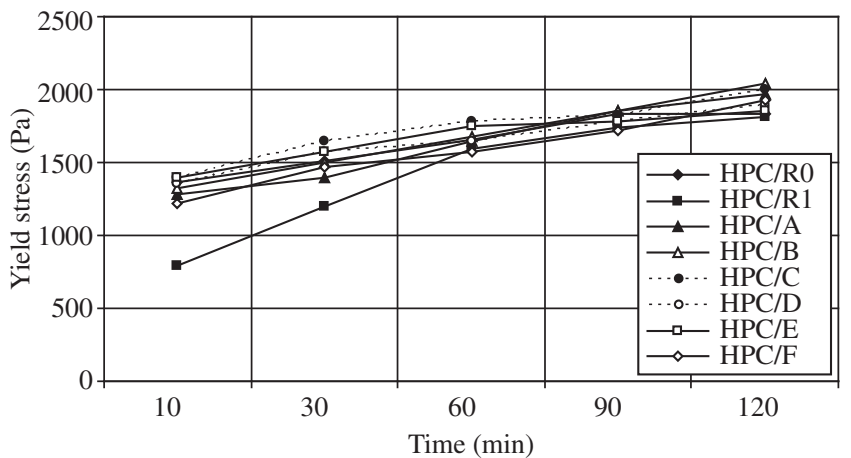

Figure 4. Curves of yield stress $v s$. time for evaluated concretes.

Table 3. Mix proportions and fresh concrete properties.

\begin{tabular}{|c|c|c|c|c|c|c|c|c|}
\hline \multirow[t]{3}{*}{ Concrete } & \multirow[t]{3}{*}{ Specific gravity $\left(\mathrm{kg} / \mathrm{dm}^{3}\right)$} & \multicolumn{7}{|c|}{ Material's consumption ( $\mathrm{kg} / \mathrm{m}^{3}$ of concrete $)$} \\
\hline & & \multirow[t]{2}{*}{ Cement } & \multirow[t]{2}{*}{ Silica fume } & \multirow{2}{*}{ Fine aggregate } & \multicolumn{2}{|c|}{ Coarse aggregate } & \multirow[t]{2}{*}{ Water } & \multirow[t]{2}{*}{ SP } \\
\hline & & & & & $\begin{array}{c}\text { Crushed } \\
\text { rock } 1\end{array}$ & $\begin{array}{c}\text { Crushed } \\
\text { rock } 2 \\
\end{array}$ & & \\
\hline HPC/R0 & 2.503 & 511 & - & 664 & 452 & 677 & 204 & - \\
\hline $\mathrm{HPC} / \mathrm{R} 1$ & 2.522 & 515 & - & 669 & 455 & 682 & 205 & 1.03 \\
\hline HPC & 2.483 & 474 & 32 & 659 & 448 & 672 & 202 & 1.01 \\
\hline
\end{tabular}


Table 4. Final slump values and partial slump times for evaluated concretes.

\begin{tabular}{|c|c|c|c|c|c|c|c|c|}
\hline \multirow[b]{2}{*}{ Time (min) } & \multicolumn{8}{|c|}{ Final slump value - in (mm) } \\
\hline & HPC/R0 & HPC/R1 & $\mathrm{HPC} / \mathrm{A}$ & $\mathrm{HPC} / \mathrm{B}$ & $\mathrm{HPC} / \mathrm{C}$ & HPC/D & $\mathrm{HPC} / \mathrm{E}$ & $\mathrm{HPC} / \mathrm{F}$ \\
\hline 10 & 140 & 220 & 150 & 145 & 135 & 140 & 135 & 160 \\
\hline 30 & 120 & 165 & 135 & 120 & 100 & 110 & 110 & 125 \\
\hline 60 & 100 & 110 & 100 & 95 & 80 & 100 & 85 & 110 \\
\hline 90 & 75 & 90 & 70 & 70 & 75 & 80 & 80 & 90 \\
\hline \multirow[t]{2}{*}{120} & 75 & 80 & 55 & 45 & 50 & 65 & 70 & 60 \\
\hline & \multicolumn{8}{|c|}{ Partial slump time - in (s) } \\
\hline 10 & 0.29 & 0.28 & 0.28 & 0.30 & 0.29 & 0.29 & 0.29 & 0.26 \\
\hline 30 & 0.35 & 0.30 & 0.31 & 0.34 & 0.35 & 0.33 & 0.32 & 0.29 \\
\hline 60 & 0.39 & 0.35 & 0.37 & - & - & 0.40 & - & 0.36 \\
\hline 90 & - & - & - & - & - & - & - & - \\
\hline 120 & - & - & - & - & - & - & - & - \\
\hline
\end{tabular}

Table 5. Values of yield stress and plastic viscosity for evaluated concretes.

\begin{tabular}{|c|c|c|c|c|c|c|c|c|}
\hline \multirow[b]{2}{*}{ Time (min) } & \multicolumn{8}{|c|}{ Yield stress $\left(\tau_{o}\right)-$ in $(\mathrm{Pa})$} \\
\hline & $\mathrm{HPC} / \mathrm{R} 0$ & $\mathrm{HPC} / \mathrm{R} 1$ & $\mathrm{HPC} / \mathrm{A}$ & $\mathrm{HPC} / \mathrm{B}$ & $\mathrm{HPC} / \mathrm{C}$ & $\mathrm{HPC} / \mathrm{D}$ & $\mathrm{HPC} / \mathrm{E}$ & $\mathrm{HPC} / \mathrm{F}$ \\
\hline 10 & 1366 & 793 & 1285 & 1321 & 1393 & 1357 & 1393 & 1214 \\
\hline 30 & 1510 & 1193 & 1393 & 1500 & 1643 & 1572 & 1572 & 1464 \\
\hline 60 & 1655 & 1593 & 1643 & 1679 & 1786 & 1643 & 1751 & 1572 \\
\hline 90 & 1835 & 1738 & 1858 & 1858 & 1822 & 1786 & 1786 & 1715 \\
\hline \multirow[t]{2}{*}{120} & 1835 & 1811 & 1965 & 2037 & 2001 & 1894 & 1858 & 1929 \\
\hline & \multicolumn{8}{|c|}{ Plastic viscosity $(\mu)-$ in (Pa.s) } \\
\hline 10 & 18.15 & 17.65 & 17.38 & 18.62 & 18.00 & 18.00 & 18.00 & 16.14 \\
\hline 30 & 21.90 & 18.92 & 19.24 & 21.11 & 21.73 & 20.48 & 19.86 & 18.00 \\
\hline 60 & 24.40 & 22.07 & 22.97 & - & - & 24.83 & - & 22.35 \\
\hline 90 & - & - & - & - & - & - & - & - \\
\hline 120 & - & - & - & - & - & - & - & - \\
\hline
\end{tabular}

noticed, reaching values similar to the other mixtures. Consequently, as observed by Nehdi, Mindess and Aïtcin ${ }^{14}$, it could be seen that the high performance concrete which has a low water/cement ratio and a high SP content (HPC/R1) lost its workability more quickly than the conventional concrete (HPC/R0). When the silica fume was incorporated, the velocity of this loss was reduced.

The effect of silica fume incorporation was also observed. The mixtures revealed less fluid than the mixtures without such a mineral additive incorporation, with a higher yield stress. Regarding the plastic viscosity, the silica fume incorporation did not have any significant influence.

As for the influence of the mixing procedure, it was observed that the rheological parameters showed some variations inside of the obtained values, which proves its sensibility to the sequence of mixing. The obtained values for the yield stress varied between $1,214 \mathrm{~Pa}$ and 1,393 $\mathrm{Pa}$ (absolute variation of $179 \mathrm{~Pa}$ and standard deviation of $69 \mathrm{~Pa}$ ), while the plastic viscosity varied between $16.14 \mathrm{~Pa} . \mathrm{s}$ and 18.62 Pa.s (absolute variation of 2.48 Pa.s and standard deviation of 0.86 Pa.s). According to the variations for each parameter, the influence of the mixing procedure was equivalent for both; in other words, the yield stress and the plastic viscosity were influenced in the same intensity.

It is worth pointing out that a lower initial yield stress does not bring about better workability over time. If the progress of the yield stress is observed in terms of the mixture being produced according to procedure $\mathrm{F}(\mathrm{HPC} / \mathrm{F})$, the yield stress which is initially measured is the lowest of all. However, after two hours of testing, the value measured for this parameter was higher until than the value measured for the mixture that presented the highest initial yield stress (HPC/E).

In terms of determining the yield stress, the modified slump test proved to be quite suitable, however when determining the plastic viscosity, this test proved to be quite inaccurate. As the partial slump time is to short (approximately hundredths of a second), the reading was committed and several mixtures can present similar viscosities, which is not always true.

Furthermore, in spite of this test being a modification of the traditional slump test to evaluate the plastic viscosity of a concrete, there was a deficiency in terms of the evaluation of this parameter over time. When the measured slump value was smaller than $100 \mathrm{~mm}$ (partial slump value established by Ferraris and de Larrard $^{13}$ ), the partial slump time determination was not feasible anymore. Thus, it was not possible to analyze the progress of the plastic viscosity in the entire test, i.e., for a period of up to 120 minutes.

Therefore, high performance concretes should be described using a rheometer, because it is precious equipment not only for research, but also for practical studies and quality-control measurements. It gives much more information than the conventional empirical tests, lowering the material and personnel expenses. Also, the information provided is more objective, as the test is fully automated and computer-controlled ${ }^{15}$. 
Besides determining the rheological behavior of these materials, the rheometer presents geometries that are especially appropriate for the evaluation of formulations during the mixture and transport, simulating turbulent flow conditions.

Thus, using a rheometer, the progress of rheological parameters can be observed with more precision and the behavior of fresh concrete can be identified from the shear rate $v s$. shear stress curve.

\section{Conclusions}

The rheological parameters, yield stress and plastic viscosity, specified from the test to determine the consistency by the modified slump test, presented, respectively, increases of $32 \%$ and $20 \%$ over time with regards to the initial determined values -10 minutes after water contact with the binders.

The incorporation of silica fume presented changes in the fresh concrete rheological properties. The concretes incorporated with silica fume resulted in less fluid mixtures, with higher yield stress and plastic viscosity. The concretes rheological properties also varied according to the mixing procedure used.

Adding the superplasticizer meant a significant reduction in the mixture yield stress, while the plastic viscosity remained practically constant.

The modified slump test presented a certain deficiency when the plastic viscosity was evaluated over time. For most of the studied mixtures, it was only possible to follow the viscosity progress for a period of up to one hour after the contact cement-mixing water. Moreover, determining the partial slump time proved to be quite inaccurate. As this time is very short (about hundredths of a second), the reading was committed and various mixtures presented similar viscosities, which is not always true.

Regarding concrete technology, each situation should be evaluated. As well as observing the compatibility between the cement and the superplasticizer (important in terms of workability), the sequence of incorporating the mixture constituents was, among the evaluated factors, the most influential concerning the fresh concrete properties. Thus, each mix design should be studied, considering the various materials that make a concrete mixture and the concrete mixing sequence.

\section{Acknowledgments}

The authors would like to thank to FAPESP - Fundação de Amparo à Pesquisa do Estado de São Paulo for the scholarship and support allowed. They would also like to thank the companies: Holcim Brasil, Grace Brasil Ltda. and Elkem Materials South America Ltda. for the donation of materials used in the present research.

\section{References}

1. Ferraris CF. Measurement of rheological properties of high performance concrete: state of the art report. Journal of Research of the National Institute of Standards and Technology. 1999; 104(5):461-478.

2. Tattersall GH, Banfill PFG. The rheology of fresh concrete. London: Pitman; 1983

3. Chappuis J. Rheological measurements with cement pastes in viscosimeters: a comprehensive approach. In: Banfill PFG, editor. Rheology of fresh cement and concrete. Proceedings of the International Conference organized by the British Society of Rheology; 1990 March 16-29; University of Liverpool, UK. London: E \& FN Spon; 1991. p. 3-12.

4. Struble L, Szecsy R, Lei W-G, Sun G-K. Rheology of cement paste and concrete. Cement, Concrete and Aggregates. 1998; 20(2):269-277.

5. Tattersall GH. Workability and quality control of concrete. London: E \& FN Spon; 1991.

6. Chidiac SE, Maadani O, Razaqpur AG, Mailvaganam N P. Controlling the quality of fresh concrete - a new approach. Magazine of Concrete Research. 2000; 52(5):353-363.

7. Petrou MF, Wan B, Gadala-Maria F, Kolli VG, Harries KA. Influence of mortar rheology on aggregate settlement. ACI Materials Journal. 2000; 97(4):479-485.

8. Tanner RI. Engineering rheology. revised ed. New York: Oxford University Press; 1988.

9. Pandolfelli VC, Oliveira IR, Studart AR, Pileggi RG. Dispersão e empacotamento de partículas: princípios e aplicações em processamento cerâmico. São Paulo: Fazendo Arte; 2000.

10. de Larrard F, Sedran T. Mixture-proportioning of high-performance concrete. Cement and Concrete Research. 2002; 32(11):1699-1704.

11. Lanos C, Laquerbe M, Casandjian C. Rheological behaviors of mortars and concretes: experimental approach. In: Bartos PJM, Marrs DL, Cleland DJ, editor(s). Production methods and workability of concrete. Proceedings of the International RILEM Conference; 1996 June 3-5; Paisley, Scotland. London: E \& FN Spon; 1996. p. 343-353.

12. Yen T, Tang C-W, Chang C-S, Chen K-H. Flow behaviour of high-strength high-performance concrete. Cement \& Concrete Composites. 1999; 21(5-6):413-424.

13. Ferraris CF, de Larrard F. Modified slump test to measure rheological parameters of fresh concrete. Cement, Concrete and Aggregates. 1998; 20(2):241-247.

14. Nehdi M, Mindess S, Aïtcin P-C. Rheology of high-performance concrete: effect of ultrafine particles. Cement and Concrete Research. 1998; 28(5):687-697.

15. de Larrard F, Sedran T, Hu C, Szitkar J C, Joly M, Derkx F. Evolution of the workability of superplasticized concretes: assessment with the BTRHEOM rheometer. In: Bartos PJM, Marrs DL, Cleland DJ, editor(s). Production methods and workability of concrete. Proceedings of the International RILEM Conference; 1996 June 3-5; Paisley, Scotland. London: E \& FN Spon; 1996. p. 377-388.

16. Castro AL. Reologia do concreto de alto desempenho. [Unpublished D. Phil thesis] São Carlos: Interunidades em Ciência e Engenharia de Materiais, Universidade de São Paulo. 